\title{
Gestão do Trabalho em Equipe nos Serviços Hospitalares
}

\author{
Ana Clara Barreiros dos Santos Lima, Isaane Lopes dos Santos, Marina Peduzzi, Pilar Spinoza
}

\section{Resumo}

Introdução: Trata-se de uma síntese de evidência de caráter exploratório que teve como objetivo identificar e analisar na literatura como é feita a gestão do trabalho em equipe nos serviços hospitalares. Método: Exploramos as bases (BVS, Pubmed, Web of Science e Cinahl) com operadores de busca (OR e AND) e os filtros texto completo, idioma (português, inglês e espanhol), sem limitação de data de publicação e humanos e, aplicados os critérios de inclusão: artigo com qualquer desenho de estudo; publicações que tratassem como tema central da gestão do trabalho em equipe nos serviços hospitalares. Resultados: Após leitura do título e resumo dos 399 artigos foram selecionados 25 artigos (BVS 04 artigos, Pubmed 11, Web of Science 03, Cinahl 07) para leitura na íntegra e análise, da qual resultaram apenas 03 artigos que respondiam ao objetivo proposto. Evidenciou-se um maior número de publicações nos últimos dois anos, em sua maioria a partir de 2015 com estudos realizados na atenção primária. Nos resultados identifica-se escassez de publicações nacionais relacionadas ao tema central do estudo no âmbito hospitalar, onde poucas organizações apoiam a prática interprofissional, uma vez que o trabalho em equipe é ainda desenvolvido de forma multiprofissional, com frágil colaboração, sem evidência de uma comunicação efetiva entre gestores e equipe, além da falta de clareza de papéis. As publicações mostram o reconhecimento de que a interdisciplinaridade e o trabalho em equipe melhoram o vínculo entre os profissionais e pacientes, contribuem para resultados positivos como: segurança, satisfação e qualidade no atendimento. Conclusão: Constatou-se a necessidade de novos estudos sobre gestão do trabalho em equipe que perpassem os aspectos burocráticos e retratem sobre as ações de gestão para o desenvolvimento do trabalho em equipe nos serviços hospitalares, contribuindo assim para o trabalho interprofissional colaborativo.

Descritores: Gerenciamento da Prática Profissional, Equipe de Assistência ao Paciente, Serviços Hospitalares 